\title{
ASPECTOS DiFERENCIAIS DAS UNIDADES DE TRADUÇÃO E TERMINOLÓGICA
}

\author{
DIFFERENT ASPECTS OF TRANSLATION AND TERMINOLOGY UNITS
}

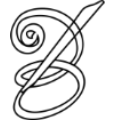 \\ Sátia Marini \\ (Mestre - POSTRAD/UnB - Brasília/Brasil) \\ smarini@mgnetdf.com.br
}

\begin{abstract}
Resumo: Durante o estudo do glossário temático de Saúde Suplementar do Ministério da Saúde, observou-se que as unidades terminológica e de tradução não tinham a mesma configuração e, a fim de abordar essas unidades também foi necessário fazer estudo sobre equivalência. Foi realizada pesquisa nos autores contemporâneos, para estabelecer as diferenças entre essas unidades, apontando os objetos de interesse particulares a cada uma delas, suas teorias e formas de delimitação. Entendemos que a equivalência trata de problemas e da estrutura da língua e dos seus aspectos socioculturais e deve ser contextualizada, que a unidade de tradução é uma unidade flexível que depende do momento de reflexão do tradutor e a unidade terminológica é uma unidade com delimitação fixada pelos próprios especialistas da área em estudo.
\end{abstract}

Palavras Chave: Tradução; Terminologia; Glossário temático.

Abstract: While studying the thematic glossary of Private Health Insurance and Plans of the Ministry of Health we observed that translation unit and terminology unit did not have the same structure. In order to address these units we also needed to talk about equivalence. Our research focused on contemporary authors, and aimed at establishing the differences between these units, pointing out the objects of particular interest to each of them, their theories and forms of delimitation. We understand that equivalence deals with problems and structures of the languages involved, and their cultural aspects and must be contextualized, that the translation unit is a flexible unit which depends on the moment the translator is experiencing and the terminology unit is a fixed form established by the experts of the studied area.

Key Words: Translation; Terminology; Thematic glossary.

\section{Introdução}

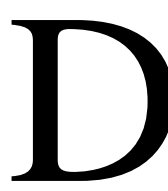

urante o trabalho de elaboração das traduções dos termos de um dos glossários do Projeto de Terminologia da Saúde (PTS), o glossário temático de Saúde Suplementar, objeto do nosso mestrado, observamos que as unidades terminológica e de tradução não tinham a mesma configuração e, para podermos fazer uma análise das traduções dos termos do glossário, houve necessidade de precisar o nosso entendimento sobre alguns termos usados em Terminologia e em Estudos da Tradução. Esses termos são: unidade terminológica (termo), unidade de tradução e equivalência, sendo que o primeiro deles tem provocado discussões menos divergentes no meio acadêmico do que os dois últimos. 
Tradução e terminologia são áreas que têm formado uma parceira ao longo de suas existências, pois mostraram-se interdependente e contribuem para o aperfeiçoamento uma da outra. A terminologia é uma disciplina moderna que apenas recentemente passou a ser tratada como área autônoma, devido ao notável crescimento do tratamento das linguagens de especialidade em um mundo em permanente inovação científica, técnica e tecnológica. Embora não seja ressaltada como uma área de estudo, a terminologia faz parte da vida das pessoas em diversas atividades do seu dia a dia, sejam elas profissionais ou não.

Segundo Barros (2004, p. 22), devido à necessidade de desenvolver terminologias nas empresas, o trabalho terminológico se ampliou do âmbito universitário para o empresarial. Além disso, é fato que o trabalho da terminologia bilíngue ou multilíngue está acelerado na atualidade devido às renovações observadas em todas as áreas do conhecimento. Associações foram criadas, as normas desenvolvidas por instituições nacionais e internacionais são adotadas pelos seus regulados e a importância desta ciência é cada vez mais reconhecida nos organismos profissionais que buscam difundir as terminologias próprias das suas áreas a fim de aperfeiçoar o entendimento e a qualidade dos seus serviços e produtos.

18 Na tradução, conforme diz Barros (BARROS, 2004, p. 47), “as pesquisas no campo da Terminologia e toda sua produção objetivam munir os tradutores de instrumentos de trabalho dotados de maior grau de precisão". É dessa precisão que os profissionais preocupados com seu ofício se munem para certificar-se de estar colocando no mercado uma produção séria, que transmita confiança para o usuário. Devido ao grande intercâmbio internacional, a terminologia bilíngue é o caminho pelo qual o conhecimento profissional se renova e se aperfeiçoa com mais rapidez, proporcionando o compartilhamento de experiências entre comunidades falantes de línguas diferentes.

Uma distinção entre terminologia bilíngue e tradução é apresentada por Aubert (2001 p. 41-52) que mostra que essas duas áreas têm uma relação de complementaridade sendo convergentes quando: a) a terminologia serve de auxílio ao tradutor (uso de glossários); b) a tradução serve como auxílio à terminologia bilíngue ou multilíngue; c) a definição é considerada uma tradução intralingual e/ou paráfrase e d) o tradutor participa como criador de terminologia.

Krieger \& Finatto (2001, p. 75) apontam como interesses da terminologia, o termo, a fraseologia e a definição, sendo o termo o "objeto privilegiado de reflexão e tratamento"; a fraseologia, "a expressão típica das comunicações profissionais"; e a definição, aquela que 
"corresponde à materialização linguística do componente conceitual do termo, funcionando como articulação linguística e via de acesso desse componente".

Como objeto de estudo da tradução apontamos principalmente o texto de partida e o texto de chegada, sendo esse último responsável por transmitir o conteúdo (e/ou a forma) do primeiro. A tradução é uma prática que se ocupa das complexas atividades cognitivas que envolvem o processo tradutório e não se limita ao texto escrito, pois estuda ainda o texto falado (atividade denominada interpretação) e as traduções intersemióticas (reprodução de um conteúdo expresso em uma linguagem para outro sistema de linguagem da mesma língua ou de outra). Seja qual for a modalidade, ao analisar as traduções, o profissional tem como foco mais imediato a unidade de tradução.

Iniciaremos nossa discussão com a polêmica sobre a equivalência para logo após abordarmos a unidade de tradução e a unidade terminológica.

\section{A controversa equivalência}

Nos Estudos da Tradução, uma questão bastante discutida refere-se à possibilidade ou impossibilidade de tradução. De forma bastante pragmática, consideramos que nos contatos entre comunidades linguisticamente diferentes, sempre ocorreu alguma forma de tradução, e, portanto, a tradução sempre esteve presente. Além disso, são inúmeras as discussões sobre equivalência, unidades de tradução, modalidades de tradução e tantos outros assuntos relacionados à área.

Um dos temas que tem comportado mais discussões e divergências nos Estudos da Tradução refere-se ao conceito de equivalência, que tem sido até mesmo tratado como circular em relação a tradução, quando Pym diz que "equivalência parece definir tradução e tradução, por sua vez, parece definir equivalência" (ROUTLEDGE, 1998, p. 77, tradução nossa) e lembra que pouco se tentou definir equivalência na tradução de forma a evitar esta circularidade. De fato, não parece ser possível falar de tradução sem mencionar a equivalência, pois este é um princípio básico do trabalho do tradutor.

Diversos autores argumentaram e se posicionaram sobre os vários entendimentos a respeito desse conceito crucial para a tradução. Albir (2001, p. 208) lembra que a "relação de equivalência entre elementos individuais de um par de textos não implica que exista equivalência textual em um plano geral", ou vice-versa. Para ela, a equivalência pode se dar em qualquer nível, entretanto, um nível sempre será mais contemplado em detrimento dos demais. 
Quanto a isso, Welker (s/data, p. 6) lembra que "o que deve ser procurado na tradução não é somente a equivalência semântica". Ele cita o lexicógrafo alemão Scholze-Stubenrecht (1995), segundo o qual deveria haver também equivalência em diversos níveis, a saber:

\begin{abstract}
estilístico (mesmo registro); pragmático (o equivalente deve poder ser usado nas mesmas situações de comunicação); terminológico (um termo técnico deve ser traduzido por um termo técnico na L2); diacrônico (um lexema antiquado deve ser traduzido por um lexema antiquado na L2); contextual (o equivalente deve poder ser usado nos mesmos co(n)textos); sintático-gramatical (o equivalente deve poder ser usado nas mesmas estruturas sintáticas, p.ex. na voz passiva); metafórico (uma metáfora deve ser traduzida por uma metáfora); etimológico (deve-se preferir equivalentes que têm a mesma origem do lexema da L1); de formação das palavras (política, político - ingl. politics, politician); de frequência (os equivalentes devem ter, nas duas línguas, o mesmo nível de frequência de uso); fonético-prosódico (importante em textos literários); diatópico (dificilmente alcançada, pois não faz muito sentido traduzir um regionalismo da L1 por um regionalismo - com conotações bem diferentes - da L2.
\end{abstract}

Tal proposta, se entendida de forma a abranger todas essas equivalências, sugere a impossibilidade de alcançar uma equivalência, uma vez que as línguas têm etimologias e 20 evoluções diferentes, bem como características regionais e pragmáticas distintas umas das outras. Essa equivalência só poderia ser imaginada numa mesma língua, na mesma situação comunicativa, envolvendo os mesmos interlocutores num momento específico, ou seja, ela ocorre uma única vez apenas, pois as situações raramente se repetem de forma idêntica, e quando isso ocorre, o momento já é outro e a condição de comunicação já está alterada. Pode-se ainda considerar a possibilidade de alguns desses níveis de equivalência serem contemplados em situações específicas, assim, elegem-se os níveis em que se pretende ter tal equivalência, e os demais são menos considerados, sendo essa uma possibilidade de obter uma equivalência para uma finalidade específica.

Para Nida existem dois tipos de equivalências. A equivalência dinâmica ativa a mesma função cultural, ou uma similar, na língua de tradução (PYM, 2010, p.8), e supõe uma maior relevância da conformidade contextual e da adequação da tradução às necessidades dos receptores e "refuta a existência de equivalências fixas, transcodificáveis, preestabelecidas de antemão fora de contexto e que possam servir para a tradução de textos" (ALBIR, 2001, p. 209 , tradução nossa). A equivalência formal imita a forma do que foi dito na língua original (PYM, 2010, p. 8), foca na mensagem original, tanto na sua forma quanto no seu conteúdo, e tem como objetivo reproduzir literalmente a mensagem do original sem adaptá-la ao novo 
público. Nida assume a posição de que a equivalência dinâmica oferece maior naturalidade ao texto.

Catford (1980, p. 23) entende que equivalência é uma "palavra-chave" na tradução e que encontrar equivalentes de tradução é um problema central nessa prática. Esse autor distingue ainda entre equivalência textual e correspondência formal, sendo o equivalente textual "qualquer texto ou porção de texto da LM [língua meta] que, [...] se observe ser numa ocasião específica o equivalente de determinado texto ou porção de texto da LF [língua fonte]" e que se baseie "no conhecimento de um informante ou tradutor bilíngue competente" (op. cit, p. 29), já o correspondente formal refere-se à categoria da LM [...] que se possa dizer que ocupa, tanto quanto possível na 'economia' da LM, o 'mesmo' lugar que determinada categoria da LF ocupa na LF" e lembra que a correspondência formal é "quase sempre aproximada", pois é definida de acordo com as relações existentes dentro de cada língua (op cit, p. 29).

Ladmiral (cf. ALBIR, 2001, p. 206) propõe o termo 'aproximação' em substituição a equivalência por entender que ele "expressa mais explicitamente a subjetividade do tradutor" (tradução nossa). Albir (op cit) também lembra que Hatim e Masom haviam proposto o termo ‘adequação' por considerarem problemático o uso do termo equivalência, pois esse indicaria um objetivo alcançável, como se realmente existisse tal equivalente, fosse ele formal ou dinâmico. Entendemos, entretanto, que uma mudança de denominação não traria uma solução determinante para a definição do termo equivalência, nem mesmo sobre as discordâncias a respeito da possibilidade dela existir.

Albir lembra ainda que "ao utilizar o termo equivalência, podemos nos referir a unidades maiores ou menores do texto original e da sua tradução" e conclui que a relação entre o original e a tradução tem um caráter relativo, dinâmico e funcional, pois depende da situação comunicativa e do contexto sócio-histórico (2001, p. 208-209). Essa autora conclui que "a busca da equivalencia em tradução é um processo complexo no qual se produz un movimento mental contínuo de associações sucessivas de ideias, deduções lógicas, tomada de decisões, etc.” (traduções nossas) (op cit, p. 211-212).

No nosso entendimento, a equivalência é estabelecida no momento da explicitação, ou seja, ao traduzir consideram-se as opções levantadas nas pesquisas e, avaliando todas as variáveis que podem influenciar a escolha, elege-se a forma mais adequada de redigir nas palavras da língua de chegada o que foi escrito na língua de partida. É uma discussão entre os 
sujeitos autor e tradutor sobre os conceitos traduzidos que estabelecerá a equivalência, o que ocorreu na tradução dos termos do glossário acima referido.

$\mathrm{Na}$ linguagem de especialidade, a equivalência é construída entre os especialistas, por meio de um compartilhamento do conhecimento adquirido. Os especialistas são os sujeitos que propõem os termos em suas línguas de acordo com o conhecimento técnico ou científico que detém sobre o assunto. Esses termos podem ter relações metafóricas diferentes em idiomas distintos, sendo relevante nesse tipo de tradução que o sentido seja o mesmo dentro da área de especialidade em questão.

De acordo com Oliveira (2007, p. 111),

\footnotetext{
a equivalência dá aos profissionais e especialmente aos alunos uma certa segurança, pelo menos para iniciar suas pesquisas. O conforto de pensar na existência de uma relação perceptível entre texto de partida e texto de chegada permite que tenham uma atitude otimista (e ilusória) frente à atividade que os aguarda.
}

Da mesma forma, as terminologias, os dicionários, as fontes de pesquisa, atualmente muito informatizadas, também conferem este conforto aos tradutores, aliviando sua angústia de busca de equivalentes que se aproximem do ideal de tradução.

Vejamos, então, os entendimentos sobre unidade de tradução para compararmos com a unidade terminológica.

\section{Unidade de tradução}

Definir ou delimitar o que é unidade de tradução (UT) é uma questão que tem sido bastante discutida e sobre a qual não se chegou a um acordo. Alves lembra a posição de Newmark a respeito de unidade de tradução que a delimita ao nível da palavra, e, depois, das expressões idiomáticas, frases, orações e períodos (ALVES, MAGALHÃES e PAGANO, 2000, p. 31). Ele diz ainda que raramente será a "nível de parágrafo e jamais a nível de texto". Por outro lado, ainda segundo Alves (op. cit, p. 30), os teóricos que estudam Análise do Discurso argumentam que a única unidade de tradução possível é o texto como um todo, cuja tradução, de acordo com a teoria da funcionalidade, deve focar principalmente na função do texto, abandonando a literalidade em favor de uma contextualização da tradução na língua de chegada. Nessas breves linhas, observamos uma discordância no que se refere ao tamanho da UT e a inexistência de um padrão aceito unanimemente para ela.

A conceituação de unidade de tradução é um problema que tem preocupado os pesquisadores, desde que Vinay e Darbelnet emitiram o conceito. Eles definiram UT como "o 
menor segmento do enunciado cujos signos têm uma coesão tal que não devam ser traduzidos separadamente" (1995, p. 21, tradução nossa).

Vários autores entendem que a UT depende do conhecimento do tradutor e será tão menor (palavra, expressão) quanto menor o conhecimento dele e tão maior (sentença, frase) quanto maior esse conhecimento. Há ainda que se considerar que a maior distância estrutural entre as línguas levará a uma UT maior, uma vez que neste caso se busca traduzir mais o sentido do que a palavra.

De acordo com Fábio Alves (op. cit., 2000, p. 38), "A unidade de tradução é um segmento do texto de partida, independente de tamanho e forma específicos, para o qual, em um dado momento, se dirige o foco de atenção do tradutor". Assim, a unidade de tradução varia de acordo com o problema encontrado pelo tradutor ao longo de sua tarefa. Será a oração ou a frase quando o tradutor, no seu processo de trabalho passar de um trecho solucionado para um novo trecho a ser traduzido. Poderá ser também um trecho da frase composto por substantivo + verbo, substantivo + preposição + complemento, verbo + preposição + complemento ou qualquer outra estrutura sintática seja ela extensa ou curta. Tudo dependerá da dúvida ou problema sobre o qual o tradutor se debruça antes de prosseguir na tradução.

Embora o tradutor possa ter necessidade de ler o texto, ou o parágrafo inteiros ou um trecho longo do texto de partida para entender o assunto e fazer considerações sobre o desenrolar da tradução, invariavelmente, a unidade de tradução na qual ele concentrará esforços para solucionar dúvidas será menor do que tal parágrafo. A UT depende do estado cognitivo do tradutor que possibilite a ele lembrar-se de alguma construção que utilizou em situação similar, verificar a terminologia, considerar a fraseologia utilizada em determinada área de conhecimento, consultar suas fontes de pesquisa, verificar as concordâncias verbal ou nominal usadas em determinada língua, entre outras possibilidades. A unidade que apresenta dificuldades será considerada a unidade de tradução em determinado momento, e nela estará concentrado o foco de atenção do tradutor.

Por vezes, as UTs podem ser reconhecidas pelas pausas feitas durante o trabalho para encontrar soluções. As dúvidas dependem das características do tradutor, do conteúdo do texto trabalhado, dos problemas que as línguas envolvidas apresentam, das dificuldades pessoais do tradutor e da sua experiência de vida. Pelas diferenças em todas essas considerações, é que se sabe ser muito improvável um mesmo texto traduzido por duas pessoas diferentes ter resultado idêntico. 
A UT também se transforma de acordo com a fase do processo tradutório, seja ela de leitura, de compreensão, de tradução propriamente dita, de revisão da tradução ou de releitura do texto a ser finalizado. Durante a revisão da tradução, momento em que, aí sim, o parágrafo ou o texto como um todo pode ser considerado a unidade de tradução (ou, quem sabe, unidade de revisão), procede-se à verificação da coerência e da coesão do texto, verifica-se a regularidade da terminologia, a fluência do texto com foco no leitor, para que a leitura não seja truncada, não pareça uma tradução.

A unidade de tradução poderá ainda ser um termo técnico utilizado em determinada linguagem de especialidade, situação em que coincidirá com o que denominamos unidade terminológica. Ou poderá ser uma única palavra com a qual o tradutor nunca tenha tido contato ou precise buscar uma acepção que desconhecia até aquele momento, para que o novo texto traduzido faça sentido. Pode ainda ser um prefixo que auxiliará o profissional a entender o significado de determinado vocábulo conhecido, mas que se apresenta no texto com este afixo alterando seu significado. Neste caso, conhecendo o vocábulo e o prefixo, o tradutor poderá inferir o significado do vocábulo novo para ele.

24 A partir da citação abaixo de Maria Teresa Cabré no prefácio do Curso Básico de Terminologia (BARROS, 2004, p. 16-17), passaremos a considerar a unidade terminológica.

\footnotetext{
A unidade de tradução não é, de forma nenhuma, a unidade terminológica, e, portanto, fazer uma pesquisa terminológica bilíngue não é partir de uma nomenclatura preestabelecida em uma dada língua por um dicionário e traduzir para outra selecionando palavras semanticamente equivalentes.
}

\section{Unidade terminológica ou termo}

o termo técnico-científico não é um elemento periférico nas comunicações especializadas. Ao contrário, é nódulo cognitivo central” (KRIEGER, 2006).

Krieger e Finatto (2004, p. 33) apresentam a distinção do entendimento do conceito de "termo" para a Teoria Geral da Terminologia (TGT) e para a Teoria Comunicativa da Terminologia (TCT). As autoras lembram que, para a TGT, os termos não pertencem às línguas naturais, "pois são compreendidos como unidades de conhecimento que comportam denominações", são rótulos, "etiquetas denominativas criadas com determinadas peculiaridades que permitem fugir das ambiguidades do léxico comum”. Já para a TCT, a princípio não existem termos, "nem palavras, mas somente unidades lexicais" (op. cit., p. 35), pois apenas quando utilizadas dentro de uma linguagem de especialidade estas se tornarão 
termos. Na TCT, os termos fazem parte da "linguagem natural e da gramática da língua" (op. cit., p. 35), o que aproxima o termo e a palavra por não terem eles diferenças estruturais significativas.

De acordo com Dubuc (2002, p. 33), a palavra "termo" corresponde aos elementos que constituem uma nomenclatura terminológica ligada a uma linguagem de especialidade, sendo, portanto, o elemento central de toda a terminologia. Então, ele concorda com Cabré (1993, p. 169) que conceitua os termos como "as unidades de base da terminologia [que] designam os conceitos próprios de cada disciplina especializada" (tradução nossa).

Barros (2004, p. 39-40), por sua vez, diz que

\begin{abstract}
A terminologia tem como unidade padrão o termo, definido pelos organismos internacionais de normalização como 'designação, por meio de uma unidade lingüística, de um conceito definida em uma língua de especialidade’ (ISO 1087, 1990, p. 5). O termo é, portanto, uma unidade lexical com um conteúdo específico dentro de um domínio específico, também chamado de unidade terminológica.
\end{abstract}

A ISO 1087-1:2000 (p. 6) fez breves alterações na definição de termo que passou a redigir da seguinte forma: “designação verbal de um conceito geral em uma área especializada específica", à qual acrescenta uma nota: "um termo pode conter símbolos e pode ter variantes, isto é, formas ortográficas diferentes".

Cabré (1993, p. 171) classifica os termos em três perspectivas diferentes: a formal, segundo a qual os termos são conjuntos fonológicos, que podem ser articulados foneticamente e representados graficamente; a semântica, que entende os termos como unidades que se referem a uma realidade e portam significado descrito por características distintivas; e a funcional, para a qual os termos são unidades distributivas relacionadas a um entorno linguístico específico e, no discurso, se combinam com outros termos específicos ao mesmo tema. Com essas classificações, ela posiciona os termos dentro da língua comum, estabelece conceitos para eles e os vincula a uma linguagem de especialidade, o entendimento da TCT.

Quanto à ligação do termo com sua noção, Dubuc (2002, p. 36) argumenta que essa relação é basicamente convencional, uma denominação arbitrária do signo linguístico. Entretanto, um termo pode ser motivado se recuperar a noção de outro termo já estabelecido anteriormente, tanto unindo dois semas com sentido previamente definido, quanto unindo um sema a um afixo novo ou palavra emprestada de outro idioma. "A motivação é útil, mas não necessária. A relação de um termo com sua noção é garantida por uma convenção estável e bem estabelecida" (op. cit., p. 36). Dubuc acrescenta que, idealmente, cada termo deve se 
relacionar a uma única noção dentro de uma língua de especialidade e esta noção deve ter apenas um termo, relação denominada biunivocidade.

Sager (1993, p. 91) diz que os termos são a "representação linguística dos conceitos" e que a sua designação dentro das linguagens de especialidade busca a transparência e consistência dos termos. Esse autor (op. cit., p. 93) reforça ainda que, atualmente, a Terminologia aceita os sinônimos e as variantes e se opõe à "atitude estritamente prescritiva do passado [leia-se, TGT] que associava um conceito a um único termo".

Segundo Dubuc (2002, p. 57),

\begin{abstract}
a unidade terminológica é a denominação de uma noção única para o domínio de estudo porque ela pertence exclusivamente a este domínio, isto é, ela não é observada em nenhum outro, pois é objeto de utilização específica neste domínio (tradução nossa).
\end{abstract}

A unidade terminológica surge dentro de uma linguagem de especialidade (LE) e pode ter uma extensão curta ou longa, pode ocorrer na língua vernácula ou em uma estrangeira, pode ser uma sigla, um neologismo, pode vir da linguagem comum ou se transformar em um vocábulo dessa e refere-se apenas ao contexto da especialidade em que foi criada. É uma unidade cuja existência é reconhecida na área de especialidade e, a partir do momento em que é correntemente usada na LE, essa frequência de uso lhe confere o estatuto de termo.

Quanto à tipologia dos termos, o número de palavras no termo é um parâmetro utilizado pelos autores para fazer uma distinção. Pavel e Nolet (2002, pp. 20 e 131) distinguem entre termos simples, aqueles formados por uma única palavra (p. ex.: Plano), que podem ser também formados por derivação (p. ex.: Adaptação) ou acronímia/sigla (p. ex.: Cadop; ANS); e termos compostos, que, por sua vez, são formados por um grupo de palavras que podem estar unidas por um hífen ou não (p. ex.: Provisões técnicas; Padrão Tiss).

Barros (2007, p. 399) classifica os termos em simples, que têm um único lexema independente do seu processo de formação; complexos, um grupo de lexemas e morfemas gramaticais não ligados por hífen; e compostos, que têm dois ou mais lexemas não autônomos (unidos por hífen).

Em Fundamentos de la Terminología, Cabré (1993, p. 176-177) distingue os termos entre simples e complexos, dependendo do número de morfemas que os compõe. Os termos simples são formados por uma única palavra (p. ex.: Plano) e podem ter origem complexa, como, por exemplo, as siglas e acrônimos. E subdivide os termos complexos em derivados, aqueles formados por adição de afixos a bases lexicais (p. ex.: Adaptação) e compostos, 
formados combinando-se duas ou mais bases lexicais (p. ex.: Contraprestação) que podem ainda ser formados por um sintagma terminológico (p. ex.: Agravo de contraprestação pecuniária). Adotamos essa classificação nas análises dos termos, todos extraídos do glossário de Saúde Suplementar do Ministério da Saúde.

Conforme a função que desempenham no discurso, Cabré (op. cit., p. 180) entende que os termos podem ser substantivos, adjetivos, verbos ou advérbios, sendo que na terminologia se observam muito mais substantivos do que outras categorias gramaticais. Quanto ao significado, podem conceituar objetos (expressos por substantivos), processos (verbos), qualidades (adjetivos) ou relações (adjetivos ou verbos). E quanto à procedência, podem ser originários do próprio vernáculo ou ser emprestados de outro idioma.

Entre os autores citados acima, observa-se uma distinção nas classificações das unidades terminológicas quanto ao número de lexemas. Entretanto, assemelha-se a distinção entre termos com uma ou com mais lexias, independentemente da denominação atribuída.

Ao tratar de termos técnicos e científicos falamos em produtos terminológicos, tanto desenvolvidos pelo próprio tradutor para uso pessoal, quanto preparados por órgãos institucionais para uso interno ou disponibilização ao público (caso do glossário de Saúde Suplementar). Os termos normatizados desses produtos tornam-se recorrentes na literatura ao serem aceitos e reconhecidos pelos usuários como soluções preferenciais para as dúvidas de tradução inerentes a qualquer trabalho de profissionais do ramo. A elaboração de dicionários e, no caso das traduções técnicas e científicas, de glossários especializados, acaba por "fixar" determinadas opções de tradução, principalmente se os produtos terminológicos são desenvolvidos por órgãos reconhecidos pelo público, como o Ministério da Saúde que elabora glossários com traduções para inglês e espanhol.

\section{Considerações finais}

As discussões sobre equivalência, apesar de recorrentes, não chegaram a uma conclusão que satisfaça a todos os teóricos, entretanto, na prática de tradução técnicocientífica, é importante considerar que o leitor espera que o conteúdo do texto de partida esteja representado na tradução de forma correspondente ao que foi dito no primeiro e de maneira fluente com a finalidade de garantir um bom entendimento para o leitor.

Palavra-chave nos Estudos da Tradução, a equivalência trata de problemas da língua, da estrutura da língua e dos seus aspectos socioculturais, e deve ser contextualizada. Para a tradução que abordamos na nossa dissertação de mestrado, sobre textos técnicos na área de 
Saúde Suplementar, é importante que se estabeleça uma equivalência de sentido, muitas vezes uma previamente homologada por órgãos reconhecidos, pois estamos falando de termos técnico-científicos e este tipo de tradução não pode levantar dúvidas quanto à veracidade da informação transmitida.

A unidade de tradução está ligada à competência do tradutor em lidar com os problemas apresentados pelas línguas com as quais trabalha. A UT pode ser a própria unidade terminológica, mas também pode ser maior ou menor do que essa ou referir-se a um trecho sem relação com uma unidade terminológica. A UT não existe na realidade e é momentânea, pois ocorre quando o tradutor percebe uma dificuldade e se dedica a buscar a solução para determinado trecho. Sua segmentação pode ser alterada conforme a necessidade do tradutor. Dependendo da competência tradutiva do profissional, a UT adquirirá uma complexidade maior e colocará o tomador de decisão na situação de resolver a dificuldade encontrada considerando todo seu conhecimento de mundo, sua competência linguística e sua habilidade para encontrar a melhor maneira de expressar o mesmo conteúdo da língua de partida na língua de chegada.

28 A unidade terminológica, por sua vez, surge na linguagem de especialidade, pode ter uma extensão curta ou longa, pode ocorrer na língua vernácula ou na estrangeira, pode ser uma sigla ou um neologismo, pode vir da linguagem comum ou se transformar em um vocábulo desta e refere-se apenas ao contexto da especialidade em que foi criada. É uma unidade que existe e é reconhecida pelos profissionais da área de especialidade. Ela passa a ser termo a partir do momento em que se percebe sua vasta utilidade, pois é a frequência de uso que lhe confere o estatuto de termo.

Unidade de tradução e terminológica, conforme observado no glossário temático de Saúde Suplementar, são conceitos diferentes que devem ser considerados ao traduzir, seja um texto literário, técnico ou científico. 


\section{REFERÊNCIAS BIBLIOGRÁFICAS}

ALBIR, Hurtado. Traductión y traductología. Madrid: Ediciones Cátedra, 2001, 695 pp.

ALVES, Fábio. (2004) Tradução, cognição e tecnologia: investigando a interface entre o desempenho do tradutor e a tradução assistida por computador. Cadernos de tradução. V. 2. No. 14. Florianópolis. 2004.

ALVES, Fábio; MAGAlHÃES, Celia; PAGANO, Adriana. Traduzir com Autonomia: estratégias para o tradutor em formação. São Paulo: Contexto, 2000.

AUBERT, Francis Henrik. Tradução técnico-científica e terminologia: um ensaio exploratório de uma via de mão dupla. TradTerm: 7, 2001. P. 41-52.

BAKER, Mona. In other words: a coursebook on translation. London and New York: Routledge. 1992.

BAKER, Mona. Routledge Encyclopedia of Translation Studies. New York: Routledge, 2009.

BARROS, Lídia Almeida. Curso básico de terminologia. São Paulo: Edusp, 2004.

CABRÉ, M.T. La terminología - teoria, metodología, aplicaciones (trad. castelhana de Carles Tebé). Barcelona: Editorial Antártida/Empúries, 529 p, 1993.

CATFORD, John Cunnison. Uma Teoria Lingǘstica da Tradução. Campinas: Cultrix,1980.

DUBUC, Robert. Manuel pratique de terminologie. Linguatech: Montreal, 4e édition 2002.

GUIDÈRE, Mathieu. Introduction à la traductologie. Bélgica : de Boeck, 2. Ed, 2011.

ISO 1087:1990 - Terminology - Vocabulary.

ISO 1087:2000 - Terminology work - Vocabulary - Part 1: Theory and application.

KRIEGER, Maria da Graça \& FINATTO, Maria José Bocorny. Introdução à Terminologia: teoria e prática. São Paulo: Contexto, 2004.

PAVEL, Sílvia; NOLET, Diane. Manual de Terminologia. Trad. de FAULSTICH, Enilde. [online]. Disponível em: www.translationsbureau.gc.ca.

PYM, Anthony. Exploring translation theories. Landon and New York. Routledge. 2010.

SAGER, Juan Carlos. Curso Prático sobre el procesamiento de la terminología Fundación Germán Sánchez Ruipérez. Madrid. Pirámide. 1993.

WELKER, Herbert Andreas. Sobre lexicografia e tradução. Disponível em: http://www.let.unb.br/hawelker/images/stories/professores/documentos/lextrad.pdf 